\title{
Development and Validation of a Short Form of the Attitude Toward Poverty Scale
}

\author{
Sung Hyun Yun \\ Robert D. Weaver
}

\begin{abstract}
This study outlines the development and validation of a short form of the 37item Attitude toward Poverty (ATP) scale. Employing a cross-sectional survey design, the authors sampled 319 undergraduate students at a mid-sized university located in central Canada. The short form evinced high levels of internal consistency ranging from .87 to .89. Evidence for the validity was established through correlational analyses and independent samples t-tests. The findings suggest the short form is a feasible alternative to the original ATP scale for researchers and academics seeking to assess the povertyrelated attitudes of university students.
\end{abstract}

Keywords: Measurement, short form development, validation, factor analysis

\section{INTRODUCTION}

A large number of studies have been conducted to investigate attitudes toward poverty and/or impoverished persons. Generally, these studies indicate the multidimensional nature of poverty-related attitudes (e.g., Cozzarelli, Wilkinson, \& Tagler, 2001; Feagin, 1972; 1975; Gil, 1981; Handler \& Hasenfeld, 1991; Karger \& Stoesz, 1990; Price, Desmond, Snyder, \& Kimmel, 1988; Rosenthal, 1993; Ryan, 1976; Shek, 2002; Smith \& Stone, 1989). Two constructs frequently identified are the individualistic and structural explanations of poverty. The individualistic explanation emphasizes individual/personal deficits as the primary cause of poverty, while the structural explanation highlights deficiencies within a market economy (DiNitto, 2000; Mullaly, 2007). Researchers have also identified the fatalistic explanation of poverty, which generally attributes poverty to uncontrollable factors such as personal misfortune and disability (e.g., Cryns, 1977; Feagin, 1972; 1975; Golding \& Middleton, 1982).

MacDonald (1971; 1972) and Feagin (1972; 1975) empirically investigated multidimensional attitudes toward poverty. The MacDonald's Poverty Scale (MacDonald, 1972, p. 118), a 12-item Likert-type scale (including five filler items), contained seven items that measure a broad combination of perceptions/stereotypes about poor people, causes of their poverty, and public policies targeting the low-income population (e.g., "Although we don't like to face it, most people on welfare are lazy"; "I can't understand why some people make such a fuss over the disadvantaged state of the poor. Most of them could improve their condition if they only tried"; "By pouring money into poverty programs we are destroying the very thing that made this a great and prosperous country: competition").

Feagin $(1972 ; 1975)$ developed an 11-item Likert-type scale that includes three dimensions: individualistic explanations, structural explanations, and fatalistic

Sung Hyun Yun, Ph.D., MSW, and Robert D. Weaver, Ph.D., are both Assistant Professors in the School of Social Work at the University of Windsor in Windsor, Ontario, CANADA.

Copyright (C) 2010 Advances in Social Work Vol. 11 No. 2 (Fall 2010), 174-187 
explanations of poverty. These three constructs identified by Feagin $(1972 ; 1975)$ have been widely used and modified in several studies which measure people's attitudes toward poverty and/or poor persons (e.g., Cozzarelli et al., 2001; Cryns, 1977; Kluegel \& Smith, 1982; Smith \& Stone, 1989). For example, Cryns (1977) modified the Feagin Poverty Scale and developed the 9-item Economic Success Scale to evaluate beliefs about reasons for economic success. The Economic Success Scale (Cryns, 1977) consists of three subscales: individualistic interpretation, structural interpretation, and fatalistic interpretation, all of which correspond to the three dimensions or constructs of the Feagin Poverty Scale outlined above.

Moreover, Cozzarelli et al. (2001) tested the three constructs (internal, external/societal, and fatalistic) originally proposed by Feagin (1972; 1975). The principal component analysis with oblique rotation confirmed the two constructs (internal and external), although the fatalistic construct was replaced by the cultural attribution or the belief about the subculture of poverty construct.

Golding and Middleton (1982) developed a 12-item scale that measures attitudes toward the causes of poverty and identified four dimensions: prodigality, injustice, ascribed deprivation, and fatalism. Prodigality represents a negative perspective toward impoverished persons, such as a belief in "the wasteful spending patterns, financial ineptitude, imprudent breeding habits and sheer fecklessness or lack of motivation of the poor" (p. 197). Injustice indicates "a positive explanation of poverty as the converse of wealth and a direct consequence of the exploitative or unfair distribution of financial reward" (p. 197). The ascribed deprivation and fatalism dimensions are alternatives to the single dimension that Feagin $(1972 ; 1975)$ identified as fatalistic. While scale items of the ascribed deprivation dimension are based on the cycle of deprivation, such as impoverished persons "never stood a chance because their parents were poor" and "come from places where there's little opportunity for most people" (Golding \& Middleton, 1982, p. 197), the fatalism items measure a belief that people are poor because of random misfortune. The fatalism construct includes such items as poor people "are just unlucky individuals" (p. 197) and "have had a bad break at some point in their lives" (p. 197). Golding and Middleton's (1982) multidimensional causes of poverty align with the three dimensions by Feagin $(1972,1975)$ outlined above, that is, the individualistic, structural, and fatalistic explanations.

Rosenthal (1993) gathered more evidence for individualistic explanations of poverty by examining graduate social work students' beliefs about poverty and attitudes toward the poor. Through the development of two scales (The Belief in the Individual Cause of Poverty scale and The Antipathy to the Poor scale), Rosenthal measured the attitudes of graduate social work students toward impoverished people. The Belief in the Individual Cause of Poverty scale is a Likert-type measure that consists of four items which reflect a belief that poverty is the result of a person's flawed characteristics rather than society's restricted opportunities. On the other hand, the Antipathy to the Poor scale, a 10-item Likert-type scale, measures an individual's propensity for disliking poor persons or avoiding situations which involve contact with them. Overall, the existing measures outlined above suggest that attitude toward poverty and poor people is multidimensional. 


\section{Unidimensionality of the Attitude toward Poverty (ATP) Scale}

In contrast to the trend of the multidimensionality of the attitude toward poverty and poor people, a unidimensional measure also exists. Atherton et al. (1993) published a brief research report on a scale for measuring university students' attitudes toward poverty. The Attitude toward Poverty (ATP) scale is a 37-item Likert-type scale that assesses attitude toward poverty and impoverished persons, with high scores indicating a belief that structural determinants are the primary causes of poverty while low scores indicate an individualistic explanation of poverty (Atherton et al., 1993). The internal consistency (Cronbach's alpha) of the original scale was .93 and the split-half (odd versus even) reliability was .87 (Atherton et al., 1993). The authors noted the ATP scale also demonstrated construct validity when they compared the response scores of social work and sociology students with business students.

Atherton et al. (1993) concluded this instrument was a single-factor scale even though they found ten factors when using the eigenvalue-greater-than-one criterion. Considering that all of the 37 items loaded high (.33 or more) on factor 1 and the eigenvalues of the ten factors were higher than one, it seems likely that a complicated factor structure (cross factor loadings) was apparent. Nonetheless, the authors did not elaborate sufficiently to justify this conclusion. Similarly, Whalen (2005) identified 13 factors using the same principal components analysis employed by Atherton et al. (1993), yet concluded, without an in-depth discussion regarding the possibility of a multidimensional factor model of the ATP, that the ATP is unidimensional. In particular, Whalen (2005) specified that in both the original and current study at least two factor eigenvalues larger than 1.0 were identified; 11.40 for factor 1 and 2.80 for factor 2 (Atherton et al., 1993) and 8.66 for factor 1 and 2.71 for factor 2 . In contrast to the results of Whalen's study, the potential multidimensionality of the ATP was verified by Rehner, Ishee, Salloum, and Velasques (1997). In their study, Rehner and colleagues determined that the ATP scale contained the following ten factors: irresponsibility; determinism; nofault circumstances; deficiency; complacency; unworthiness; identification; paternalism; denigration; and lost rights.

\section{Purpose of the Study}

The contradictory findings regarding the dimensionality of the ATP scale prompted the authors' interest in clarifying how many dimensions this measure actually contains. The authors supposed that the ATP would contain more than one factor. This hypothesis was made after reviewing the literature and the number of items and factors found in comparable measures, such as Feagin's scale (1972, 11 items, three factors), Cryns' scale (1977, nine items, three factors), and Golding and Middleton's scale (1982, 12 items, four factors). Considering 37 items too numerous to be exclusively loaded on only one factor without cross-loadings (e.g., Rehner et al., 1997; Whalen, 2005), the authors aimed to retain only necessary items without cross-loading by using a series of factor retention procedures. These procedures included the eigenvalue-greater-than-one rule (Kaiser, 1960), Cattell's scree test (Cattell, 1966), and Velicer's minimum average partial method (MAP; Velicer, 1976). These procedures were selected in order to answer the authors' questions regarding factor dimensionality and to produce a short form that could be 
administered more quickly than the original 37 -item scale. Therefore, the objectives of this study were to: (1) identify the multidimensionality of the original 37-item ATP scale; (2) generate an alternative short form that has compatible levels of reliability with the original 37-item ATP scale; and (3) establish evidence for the validity of this short form to determine its suitability for measuring the poverty-related attitudes of university students.

\section{METHODS}

\section{Design and Participants}

A cross-sectional survey research design was used in this study. The survey was administered at the beginning of a fall semester at a mid-sized university located in central Canada. Prior to the inception of the data collection phase, the authors received approval from the host university's Research Ethics Board (REB). The participants were informed that the study was voluntary and that they could withdraw at anytime without consequence. Three hundred and nineteen students participated in the study. The participants were selected from a total of 389 undergraduate students enrolled in one of three selected social work courses (two introductory and one third-year). Of this group of students, 329 met the authors' inclusion criterion that required students to major in a social science or human service profession, such as social work, psychology, sociology, political science, criminology, or nursing. The authors excluded sixty students because they either did not specify a major $(n=49)$ or they reported a major that differed from those outlined above $(n=11)$. Furthermore, ten students were removed from the data since their response scores were determined to be outliers through Normtest (DeCarlo, 1997). In cases where respondents did not respond to some of the scale items, the authors replaced the missing values with the mean of the response values for that specific scale item. The authors did not exclude any cases due to an inordinate number of missing items, since none of the cases exceeded their pre-determined threshold of expulsion, that is, $15 \%$ or more items missing on the original 37-item scale (Johnson, 2003).

The mean age of the sample was 21.5 years $(S D=5.3)$. Two hundred and seventyone $(85.0 \%)$ of the participants were female while $48(15.0 \%)$ were male. As for ethnicity, the participants were primarily Caucasian $(n=221 ; 69.3 \%)$, followed by AfricanCanadian/Black $(n=31 ; 9.7 \%)$ and then Asian $(n=14 ; 4.4 \%)$. The median income for an individual student and her/his family was $\$ 9,000$ and $\$ 80,000$, respectively. The majority of the participants $(n=253 ; 79.4 \%)$ reported they were financially secure when the survey was administered. Refer to Table 1 for a complete demographic profile of the participants. 
Table 1. Socio-Demographic Characteristics $(\mathrm{N}=319)$

\begin{tabular}{|c|c|}
\hline Demographic Variable & Characteristic \\
\hline \multicolumn{2}{|l|}{ Age } \\
\hline$M$ & 21.5 \\
\hline$S D$ & 5.3 \\
\hline \multicolumn{2}{|l|}{ Income } \\
\hline Individual Gross Income (Median) & $\$ 9,000$ \\
\hline Family Gross Income (Median) & $\$ 80,000$ \\
\hline \multicolumn{2}{|l|}{ Gender } \\
\hline Female & $271(85.0 \%)$ \\
\hline Male & $48(15.0 \%)$ \\
\hline \multicolumn{2}{|l|}{ Ethnicity } \\
\hline Caucasian & $221(69.3 \%)$ \\
\hline African-Canadian/Black & $31(9.7 \%)$ \\
\hline Asian & $14(4.4 \%)$ \\
\hline Multiethnic & $13(4.1 \%)$ \\
\hline Middle Eastern & $6(1.9 \%)$ \\
\hline Indo-Canadian & $6(1.9 \%)$ \\
\hline Aboriginal & $6(1.8 \%)$ \\
\hline Other & $22(6.7 \%)$ \\
\hline \multicolumn{2}{|l|}{ Religion } \\
\hline Catholicism & $139(43.6 \%)$ \\
\hline Protestantism & $74(23.2 \%)$ \\
\hline Islam & $12(3.8 \%)$ \\
\hline Orthodox & $10(3.1 \%)$ \\
\hline Buddhism & $3(.9 \%)$ \\
\hline Hinduism & $3(.9 \%)$ \\
\hline None & $46(14.4 \%)$ \\
\hline Other & $31(9.7 \%)$ \\
\hline Missing & $1(.3 \%)$ \\
\hline \multicolumn{2}{|l|}{ Political Affiliation } \\
\hline Conservative & $49(15.4 \%)$ \\
\hline Liberal & $133(41.7 \%)$ \\
\hline Social Democrat & $26(8.2 \%)$ \\
\hline Socialist & $8(2.5 \%)$ \\
\hline None & $91(28.5 \%)$ \\
\hline Other & $8(2.5 \%)$ \\
\hline Missing & $4(1.3 \%)$ \\
\hline \multicolumn{2}{|l|}{ Financial Security } \\
\hline Very secure & $42(13.2 \%)$ \\
\hline Secure & $116(36.4 \%)$ \\
\hline Somewhat secure & $95(29.8 \%)$ \\
\hline Somewhat insecure & $42(13.2 \%)$ \\
\hline Insecure & $13(4.1 \%)$ \\
\hline Very insecure & $8(2.5 \%)$ \\
\hline Missing & $3(.9 \%)$ \\
\hline
\end{tabular}




\section{Measurement Modification}

The ATP scale, developed by Atherton et al. (1993), was used in this study. In the authors' judgment, there were two items on the original scale developed by Atherton et al. (1993) that required modification in order to better reflect the Canadian context. These items were "An able-bodied person using food stamps is ripping off the system" (p. 29) and "Poor people use food stamps wisely" (p. 29). Given that the Food Stamp Program is an American scheme not delivered by the Canadian welfare state (Lightman, 2003), the authors, after consulting with four Canadian social work academics (three at the full professor rank and all of whom had earned a graduate level social work degree in the United States), replaced the term 'food stamps' with 'welfare benefits' in the items outlined above.

\section{Construction and Validation of the Alternative Short Form}

In order to retain/discard items and identify the number of factors, the authors used the eigenvalue-greater-than-one criterion (Kaiser, 1960), the conventional factor-loadinggreater-than .40 criterion, the Keil-Wrigley criterion (Keil \& Wrigley, 1960), reliability analysis, and the scree test (Catell, 1966). Specifically, principal axis factoring was conducted in order to maximize the covariance extracted by each successive factor. The authors chose the promax (kappa $=6)$ solution because the scale items were expected to moderately correlate with each other. Items with factor loading less than .40 were discarded, while retained items were further tested for exclusion in order to reach the highest level of reliability (the corrected item-total correlation). The authors proposed the three-factor solution because the fourth factor (and above) did not have at least three salient loadings, as determined by the Keil-Wrigley criterion (Keil \& Wrigley, 1960). The number of factors was evaluated by the scree plot and the interpretability of factors.

The authors established evidence for internal consistency for the short form and convergent validity between the original 37-item ATP scale and the short form. In addition, evidence for the known-groups validity was established through investigating the response differences between students who identified themselves as politically leftwing (i.e., liberals/social democrats/socialists) from those who identified themselves as politically right-wing (i.e., conservatives).

\section{RESULTS}

\section{Preliminary Analysis}

The authors tested the data for univariate and multivariate normality. A common guide for normal distribution is if univariate skewness and kurtosis are less than $|2.0|$ and $|7.0|$, respectively. According to these conventional cut-offs, all of the items were within the accepted normal distribution parameters.

In order to test for multivariate normality, the authors conducted Normtest (DeCarlo, 1997) and examined the suitability of the data for factor analysis by using the KaiserMeyer-Olkin (KMO) measure of sampling adequacy (Kaiser, 1970), as well as Bartlett's test of sphericity (Bartlett, 1950). The results showed that the KMO value for the data 
was .92, which is greater than Kaiser's (1970) recommended value of .6, suggesting the variability in the data was sufficient for conducting factor analysis. Bartlett's test of sphericity (1950) was statistically significant, which indicated that the variables were not independent. Hence, the data were deemed appropriate for conducting factor analysis.

\section{ATP Short Form Development}

The eigenvalue-greater-than-one criterion initially extracted five factors for the ATP Short Form (eigenvalues: 5.88, 1.78, 1.39, 1.07, and 1.04); however, the last two factors were dropped because they lacked at least three salient loadings, as determined by the Keil-Wrigly criterion (Keil \& Wrigley, 1960). The three factor solution was also confirmed after discarding 12 items that were less than the factor loading cut-off criteria (.40). Initially, there were 11 items for factor 1, eight items for factor 2, and six items for factor 3 . From factor 1 , three more items were eliminated to increase the alpha coefficient from .76 to .82 , while one item was removed from factor 2 , which resulted in an increase in the alpha coefficient from .62 to .75 . All items were retained for factor 3 because item expulsion did not improve the alpha coefficient (.67). The factor structure of the 21-item short form of the original ATP scale is demonstrated in Table 2. All of the factor loadings of the three factors were equal or higher than .40: factor $1(.44-.76)$, factor $2(.40-.81)$, and factor $3(.50-.60)$. The authors also administered the scree test (Catell, 1966) and found a linear decline commencing with the fourth factor, which supports the three factor solutions: factor 1 (personal deficiency), factor 2 (stigma), and factor 3 (structural perspective).

The alpha coefficient for the total 21 items, which included factors 1,2 , and 3 , was .87 (see Table 3). To compute the alpha coefficient for the total 21 items, the authors reversed the item scores for factor 3 because the items in factor 3 reflected structural explanations for poverty while factors 1 and 2 were individualistic and discriminatory explanations of poverty, respectively.

\section{Validity}

Convergent validity. Evidence for convergent validity was established by examining the correlation coefficients between the original 37-item scale and the ATP Short Form. Table 4 shows that the original 37-item ATP scale had statistically significant correlations across the ATP Short Form and its three subscales. All the subscales of the ATP Short Form had high positive correlations with the original 37-item ATP scale, ranging from .76 to .85 , except for factor 3 that was negatively correlated (-.30). 
Table 2: $\quad$ ATP Short Form (21 Items) Factor Structure and Loadings

\begin{tabular}{|c|c|c|c|}
\hline \multirow{2}{*}{ Scale Item } & \multicolumn{3}{|c|}{ Factor } \\
\hline & Factor $1^{\mathrm{a}}$ & Factor $2^{b}$ & Factor $3^{c}$ \\
\hline Poor people are different from the rest of society. & .76 & -.26 & -.01 \\
\hline Poor people are dishonest. & .65 & -.20 & -.19 \\
\hline Most poor people are dirty. & .64 & .04 & .01 \\
\hline Poor people act differently. & .60 & .13 & .28 \\
\hline Children raised on welfare will never amount to anything. & .54 & .01 & .00 \\
\hline $\begin{array}{l}\text { I believe poor people have a different set of values than do } \\
\text { other people. }\end{array}$ & .48 & .14 & .08 \\
\hline $\begin{array}{l}\text { Poor people generally have lower intelligence than nonpoor } \\
\text { people. }\end{array}$ & .44 & -.06 & -.05 \\
\hline There is a lot of fraud among welfare recipients. & -.15 & .81 & .13 \\
\hline $\begin{array}{l}\text { Some "poor" people live better than I do, considering all } \\
\text { their benefits. }\end{array}$ & -.12 & .77 & .19 \\
\hline Poor people think they deserve to be supported. & .13 & .63 & .27 \\
\hline Welfare mothers have babies to get more money. & .17 & .53 & .01 \\
\hline $\begin{array}{l}\text { An able-bodied person collecting welfare is ripping off the } \\
\text { system. }\end{array}$ & -.15 & .51 & -.26 \\
\hline $\begin{array}{l}\text { Unemployed poor people could find jobs if they tried } \\
\text { harder. }\end{array}$ & -.01 & .46 & -.22 \\
\hline Welfare makes people lazy. & .17 & .45 & -.18 \\
\hline $\begin{array}{l}\text { Benefits for poor people consume a major part of the } \\
\text { federal budget. }\end{array}$ & .07 & .40 & -.23 \\
\hline People are poor due to circumstances beyond their control. & .08 & .09 & .60 \\
\hline $\begin{array}{l}\text { I would support a program that resulted in higher taxes to } \\
\text { support social programs for poor people. }\end{array}$ & -.02 & -.04 & .60 \\
\hline If I were poor, I would accept welfare benefits. & .07 & .18 & .58 \\
\hline $\begin{array}{l}\text { People who are poor should not be blamed for their } \\
\text { misfortune. }\end{array}$ & .00 & .02 & .51 \\
\hline Society has the responsibility to help poor people. & -.07 & .00 & .51 \\
\hline Poor people are discriminated against. & -.02 & .20 & .50 \\
\hline $\begin{array}{l}\text { Note. Factor loadings } \geq .40 \text { are in boldface. Principal Axis } \mathrm{I} \\
\text { a Factor } 1=\text { Personal Deficiency } \\
{ }^{\mathrm{b}} \text { Factor } 2=\text { Stigma } \\
{ }^{\mathrm{c}} \text { Factor } 3=\text { Structural Perspective }\end{array}$ & & & \\
\hline
\end{tabular}


Table 3: Internal Consistency Reliability (Alpha Coefficient) of the ATP Short Form

\begin{tabular}{lc}
\multicolumn{1}{l}{ Scale } & Alpha Coefficients \\
\hline ATP Short Form (21 Items - Total) & $.87^{\mathrm{a}}$ \\
Factor 1: Personal Deficiency (7 Items) & .82 \\
Factor 2: Stigma (8 Items) & .75 \\
Factor 3: Structural Perspective (6 Items) & .67
\end{tabular}

Note. $N=319$.

${ }^{a}$ The alpha coefficient of the ATP Short Form (Total) was computed after reversing the response scores of the Factor 3 items because they reflect attitudes that are opposite to the items of both Factors 1 and 2.

Table 4: $\quad$ Correlations between the Original 37-item ATP Scale and the ATP Short Form

\begin{tabular}{|c|c|}
\hline Scale & Correlations \\
\hline ATP Short Form (21 Items - Total) ${ }^{b}$ & $.826^{*}$ \\
\hline Factor 1: Personal Deficiency (7 Items) & $.846^{*}$ \\
\hline Factor 2: Stigma (8 Items) & $.762^{*}$ \\
\hline Factor 3: Structural Perspective (6 Items) & $-.302^{*}$ \\
\hline
\end{tabular}

Note. The correlation between the ATP Short Form (total) and the original ATP scale was computed after reversing the response scores of the Factor 3 items because they reflect attitudes that are opposite to the items of both Factors 1 and 2. $N=319$.

${ }^{*}$ Correlation is significant at the 0.05 level (2-tailed).

Known groups validity. The literature indicates that measures of attitudes toward poverty and impoverished persons usually include conceptually distinct explanations such as individualism and structuralism (Cozzarelli et al., 2001; Gil, 1981; Handler \& Hasenfeld, 1991; Price et al., 1988; Ryan, 1976; Shek, 2002). Furthermore, there is empirical evidence which supports the relationship between political affiliation and attitudes toward poverty and impoverished persons (e.g., AuClaire, 1984; Davis, 1988; Handler \& Hasenfeld, 1991; Ryan, 1976). 
In our study, evidence for known-groups validity was established by investigating the attitudinal differences between students who identified themselves as politically left-wing (liberals/socialists), and those who identified themselves as politically right-wing (conservatives). An independent-samples $t$-test (one-tailed) was conducted to evaluate whether students who identified themselves as politically left-wing reported more structural attitudes toward poverty and impoverished persons than students who identified themselves as politically right-wing. Table 5 shows that the ATP Short Form could successfully differentiate between political orientation and attitude toward poverty and poor persons.

Table 5: $\quad$ Summary of Study Outcome Measures and Critical Comparison

\begin{tabular}{lccccc}
\hline & $M$ & $S D$ & $t$ & $d f$ & Sig. (one-tailed) \\
\hline ATP Short Form (Total) & & & & & \\
& & & & & \\
$\quad \begin{array}{l}\text { Politically Right Wing }(n=49) \\
\quad \text { Conservatives) }\end{array}$ & 70.0 & 9.7 & -3.5 & 214 & .000 \\
$\quad \begin{array}{l}\text { Politically Left Wing }(n=167) \\
\text { (Liberals/Social Democrats/Socialists) }\end{array}$ & 75.6 & 10.2 & & & \\
\hline
\end{tabular}

\section{DISCUSSION}

In this study, the authors described the development of the short form of the original 37-item ATP scale (Atherton et al., 1993) that measures people's attitudes toward poverty and poor people. The authors identified the presented ATP Short Form as a robust alternative to the original ATP scale. The factor structure shows that all the items within the ATP Short Form had salient factor loadings on their respective factors equal to or greater than a cut-off of .40 . In addition to establishing its reliability, the validity of the ATP Short Form was established through correlational analyses and independent samples $t$-tests.

The multidimensionality of the ATP Short Form was theoretically examined and empirically tested. The ATP Short Form includes three factors (personal deficiency -7 items, stigma -8 items, and structural perspective -6 items), which measure a range of diverse attitudes toward poverty and poor people. In contrast to the unidimensionality reported by Atherton et al. (1993), the present study developed a theoretically and statistically sound alternative, the multidimensional ATP Short Form.

The authors' preliminary psychometric analyses indicated a high level of internal consistency (Cronbach's alpha) for the alternative ATP Short Form $(\alpha=.87)$. All of the subscales of the ATP Short Form exceeded the minimum acceptable level for internal consistency between 0.50 and 0.70 (Bowling, 2002).

Evidence for convergent validity was established by investigating the correlational relationships between the original 37-item scale with the ATP Short Form $(r=.83)$. 
Factor 3 (structural perspective) of the ATP Short Form had a significant negative correlation $(r=-.30)$ with the original 37-item scale, while the other subscales were positively correlated with the original scale (between .76 and .85). This is most likely due to the fact that factor 3 of the ATP Short Form includes a unique dimension that measures a structural explanation of poverty, which is conceptually distinct from the personal deficiency and stigma perceptions of poverty. Evidence for known-groups validity was also supported because the independent samples $t$-test (one-tailed) suggested that students with a left-leaning political orientation demonstrated a more structural attitude toward poverty and poor people than did right-leaning students.

Despite the promising and clear findings regarding psychometric properties, there were limitations to this study. For instance, a convenience sample of university students who were primarily female, white, and middle class was used. Hence, replication studies with various populations who differ in terms of age, gender, ethnicity, socio-economic status and political affiliation are necessary to boost the generalizability of this study's results. In addition, confirmatory factor analysis should be conducted within these replication studies in order to further establish evidence for the three constructs detected within the ATP Short Form.

The ATP Short Form, due to its reduced number of items, is potentially easier to administer and thus more efficient in collecting data than the original 37-item ATP scale. Furthermore, the multidimensionality of the ATP Short Form allows researchers to measure students' attitude toward poverty and impoverished persons in a much more comprehensive and accurate manner than the original ATP scale.

It is vital that university students aiming to work in the human service professions are sensitized to issues surrounding social justice, and the liberation and empowerment of under-served and under-represented population groups within society, including people experiencing poverty. This is because their attitudes will dictate the policy, programmatic, and practice decisions they make as human service professionals which, in turn, can either empower or harm low-income persons (Krumer-Nevo, Weiss-Gal, \& Monnickendam, 2009; Mullaly, 2007).

The accreditation standards of social work programs within North America emphasize the importance of promoting social and economic justice and nondiscrimination. For example, the Council on Social Work Education's (CSWE) Educational Policy and Accreditation Standards (EPAS) maintain that social work programs should provide curricula that foster the implementation of strategies that combat discrimination, oppression, economic deprivation and that promote social and economic justice (2001). Specifically, the EPAS states that social work education should help "prepare social workers to alleviate poverty, oppression, and other forms of social injustice" (p. 10). Furthermore, the Canadian Association of Social Work Education (CASWE) Standards for Accreditation (2008) emphasize that "the curricula should reflect social work values that promote a professional commitment to analyze and eradicate oppressive social conditions" (p. 8). In light of these guidelines, the authors propose that the ATP Short Form developed in this study can assist university educators in detecting if their pedagogical efforts are sensitizing students to the structural 
determinants of poverty, and thus boosting the likelihood of their becoming professionals that are committed to poverty reduction efforts.

\section{References}

Atherton, C. R., Gemmel, R. J., Haagenstad, S., Holt, D. J., Jensen, L. A., O'Hara, D. F., et al. (1993). Measuring attitudes toward poverty: A new scale. Social Work Research and Abstracts, 29(4), 28-30. Retrieved from http://search.ebscohost.com.ezproxyuwindsor.ca/login.aspx?direct=true\&db=a9h\&A $\mathrm{N}=9609194559 \&$ site $=$ ehost-live

AuClaire, P. A. (1984). Public attitudes toward social welfare expenditures. Social Work, 29(2), 139-144. Retrieved from http://search.ebscohost.com.ezproxy.uwindsor.ca/login.aspx?direct=true $\& d b=a 9 h \& A$ $\mathrm{N}=5273831 \&$ site $=$ ehost-live

Bartlett, M. S. (1950). Tests of significance in factor analysis. British Journal of Psychology, Statistical Section, 3, 77-85.

Bowling, A. (2002). Research methods in health: Investigating health and health services $\left(2^{\text {nd }}\right.$ ed.). Buckingham: Open University Press.

Canadian Association for Social Work Education. (2008, May). CASWE Standards for Accreditation. Ottawa, ON: CASWE-ACFTS. Retrieved from www.caswe-acfts.ca

Cattell, R. B. (1966). The scree test for number of factors. Multivariate Behavioral Research, 1(2), 245-276.

Council on Social Work Education. (2001). Education Policy and Accreditation Standards of the Council on Social Work Education. Retrieved from http://www.wheelock.edu/socialwork.sw policy.pdf

Cozzarelli, C., Wilkinson, A. V., \& Tagler, M. J. (2001). Attitudes toward the poor and attributions for poverty. Journal of Social Issues, 57, 207-227.

Cryns, A. G. (1977). Social work education and student ideology: A multivariate study of professional socialization. Journal of Education for Social Work, 13, 44-51.

Davis, L. F. (1988). Rural attitudes toward public welfare allocation. Human Services in the Rural Environment, 12(2), 11-19.

DeCarlo, L. T. (1997). On the meaning and use of kurtosis. Psychological Methods, 2 , 292-307.

DiNitto, D. M. (2000). Social welfare: Politics and public policy $\left(5^{\text {th }}\right.$ ed.). Boston, MA: Allyn \& Bacon.

Feagin, J. R. (1972, November). Poverty: We still believe that God helps those who help themselves. Psychology Today, 101-129.

Feagin, J. R. (1975). Subordinating the poor: Welfare and American beliefs. Englewood Cliffs, NJ: Prentice Hall. 
Gil, D. G. (1981). Unraveling social policy: Theory, analysis, and political action toward social equality. Rochester, VT: Schenkman.

Golding, P., \& Middleton, S. (1982). Images of welfare: Press and public attitudes to poverty. Oxford: Martin Robertson.

Handler, J. F., \& Hasenfeld, Y. (1991). The moral construction of poverty: Welfare reform in America. Newbury Park, CA: Sage.

Johnson, M. L. (2003). Lose something? Ways to find your missing data. Retrieved from www.hsrd.houston.med.va.gov/Documents/MJ\%20Missing\%20Data\%20PDS\%2009 1703.ppt

Kaiser, H. (1960). The application of electronic computers to factor analysis. Educational and Psychological measurement, 20, 141-151.

Karger, H. J., \& Stoesz, D. (1990). American social welfare policy: A structural approach. New York: Longman.

Keil, D., \& Wrigley, C. (1960). Effects upon the factorial solution of rotating varying number of factors. American Psychologist, 15, 383-394.

Kluegel, J. R., \& Smith, E. R. (1982). Whites' beliefs about Blacks'opportunity. American Sociological Review, 47, 518-532.

Krumer-Nevo, M., Weiss-Gal, I., \& Monnickendam, M. (2009). Poverty-aware social practice: A conceptual framework for social work education. Journal of Social Work Education, 46(2), 225-243.

Lightman, E. (2003). Social policy in Canada. Don Mills, Ontario: Oxford University Press.

MacDonald, A. P. Jr. (1971). Relation of birth order to morality types and attitudes toward the poor. Psychological Reports, 29, 732.

MacDonald, A. P. Jr. (1972). More on the protestant ethic. Journal of Consulting and Clinical Psychology, 39(1), 116 - 122.

Mullaly, B. (2007). The new structural social work ( $3^{\text {rd }}$ ed.). Don Mills, Ontario: Oxford University Press.

Price, J. H., Desmond, S. M., Snyder, F. F., \& Kimmel, S. R. (1988). Perceptions of family practice residents regarding health and poor patients. Journal of Family Practice, 27(6), 615-21.

Rehner, T., Ishee, J., Salloum, M., \& Velasques, D. (1997). Mississippi social workers' attitudes toward poverty and the poor. Journal of Social Work Education, 33(1), 131142 .

Rosenthal, B. S. (1993). Graduate social work students' beliefs about poverty and attitudes toward the poor. Journal of Teaching in Social Work, 7(1), 107-121.

Ryan, W. (1976). Blaming the victim. New York: Vintage. 
Shek, D. T. (2002). Chinese adolescents' explanations of poverty: The perceived causes of poverty scale. Adolescence, 37(148), 789-803.

Smith, K. B., \& Stone, L. H. (1989). Rags, riches, and bootstraps: Beliefs about the causes of wealth and poverty. The Sociological Quarterly, 30(1), 93-107.

Velicer, W. F. (1976). Determining the number of components from the matrix of partial correlations. Psychometrika, 41, 321-327.

Whalen, M. H. (2005). Measuring MSW student attitudes toward poverty and the poor: A tool for evaluating social work education outcomes. Unpublished doctoral dissertation, Michigan State University, East Lansing, MI.

\section{Author's note:}

Address correspondence to: Sung Hyun Yun, Assistant Professor, School of Social Work, University of Windsor, 401 Sunset Avenue, Windsor, ON N9B 3P4, Canada. Email:

yshhsy@uwindsor.ca. The authors would appreciate being contacted by anyone planning on using the ATP short form. 